\title{
Sala de Aula Invertida com Auxílio do WhatsApp
}

\author{
Ernane Rosa Martins ${ }^{1}$, Luís Manuel Borges Gouveia ${ }^{2}$ \\ ${ }^{1}$ Instituto Federal de Goiás (IFG) \\ Caixa Postal 72.811-580 - Luziânia - GO - Brasil \\ ${ }^{2}$ Universidade Fernando Pessoa (UFP) \\ Caixa Postal 4249-004 - Porto - Portugal \\ ernane.martinseifg.edu.br, lmbgeufp.edu.pt
}

\begin{abstract}
This article aims to present a teaching experience conducted in a public educational institution in the disciplines of Project Management and Information Systems Projects, which may serve as a reference to new activities. The work involved the use of the Inverted Classroom Theory with the aid of WhatsApp application, accessed via Mobile Technology. At the end, a survey was applied to the students through an electronic questionnaire, obtaining 44 answers. It was found that the application can be used as a pedagogical resource, by creating groups in which there is the participation of the responsible teacher, helping in the learning process of the students.
\end{abstract}

Resumo. Este artigo tem como objetivo apresentar uma experiência de ensino realizada em uma instituição pública de ensino nas disciplinas de Gerência de Projetos e Projetos de Sistemas de Informação, que poderá servir como referência a novas atividades. O trabalho envolveu a utilização da Teoria da Sala de Aula Invertida com auxílio do aplicativo WhatsApp, acessado via Tecnologia Móvel. Ao final foi aplicada uma pesquisa junto aos discentes por meio de um questionário eletrônico, obtendo-se 44 respostas. Verificou-se que o aplicativo pode ser utilizado como um recurso pedagógico, por meio da criação de grupos nos quais existe a participação do docente responsável, auxiliando no processo de aprendizagem dos alunos.

\section{Introdução}

A sala de aula invertida (Flipped Classroom), é o conceito em que, o que antes era feita na sala de aula no modelo tradicional, agora é executado em casa, enquanto que as atividades que eram realizadas sozinhas pelos alunos como tarefa de casa, agora são executadas em sala de aula (Bergmann \& Sams, 2016). Nesta metodologia, o aluno tem o primeiro contato com o conteúdo virtualmente, fora da escola, e posteriormente discute e tira dúvidas durante a aula. M-learning (aprendizagem com mobilidade) se refere ao processo de aprendizagem apoiado pelo uso de tecnologias da informação ou comunicação móveis e sem fio, onde a característica principal é a mobilidade dos alunos (Saccol et al., 2011). A aprendizagem móvel, envolve o uso das tecnologias móveis, isoladas ou combinadas com outras tecnologias de informação e comunicação, possibilitando a aprendizagem a qualquer hora e em qualquer lugar (Unesco, 2014). 
As Novas Tecnologias da Informação e Comunicação estão cada vez mais sendo utilizado por jovens de diversas classes sociais, em especial a ferramenta WhatsApp, por exemplo, sendo inegável o grande número de pessoas que fazem uso deste aplicativo, onde realizam conversas, trocam mensagens escritas, enviam músicas, fotos e vídeos sem nenhum tipo de custo, além de possibilitar a criação de grupos, que possibilitam uma rápida troca de informações entre indivíduos, de maneira nunca antes visto, o que se torna muito importante no processo de construção do conhecimento (Souza, 2015). Moran (2015), afirma que o aplicativo apresenta uma linguagem familiar, espontânea, com a facilidade da utilização de textos, imagens, vídeos e áudios. Sendo assim, este trabalho propôs investigar a utilização da Teoria da Sala de Aula Invertida com o auxílio do WhatsApp via Tecnologia Móvel.

\section{Metodologia}

A pesquisa baseia-se em um estudo de caso de natureza qualitativa e quantitativa, de abordagem exploratória e descritiva, com pesquisa documental e questionários. Segundo Yin (2003), os estudos de caso descrevem um fenômeno ou intervenção no contexto em que ocorre. A revisão bibliográfica permitiu levantar informações sobre o assunto, estabelecendo a direção a ser percorrida e a formulação da questão de pesquisa. Os alunos acessaram e disponibilizam os conteúdos em um grupo do WhatsApp, o qual foi utilizado como ferramenta de aprendizado e posteriormente com a aplicação de um questionário eletrônico junto aos discentes, obteve-se 44 respostas dos alunos da disciplina de Gerência de Projetos e Projetos de Sistemas de Informação. O formulário utilizado foi criado no Google Docs. A análise foi realizada com base na atuação dos alunos, para saber se houve mudanças de comportamento, aquisição de competências que possibilitem a evolução ou não no aprendizado e no ensino das disciplinas.

\section{Resultados}

O projeto durou oito semanas, com vários conteúdos programáticos do currículo. Os discentes apresentaram uma participação ativa na troca de mensagens no grupo criado. Todos os alunos responderam que possuíam smartphone e os utilizaram para realizar as pesquisas e estudos. Os alunos relataram em sua maioria $(93,2 \%)$ que não encontraram dificuldades, o restante $(6,8 \%)$ disseram que tiveram dificuldades na compreensão sobre o conteúdo, necessitando de explicações prévias e presenciais. Todos disseram que não enfrentaram dificuldades em relação ao tamanha da tela dos aparelhos móveis, resolução do visor, em ler as informações ou assistir vídeos nos aparelhos celulares. Questionados sobre quais os aspectos positivos para o seu aprendizado, relataram: "facilitou o estudo em qualquer lugar e horário que estivesse disponível", "A praticidade de ter conteúdos em vários formatos como vídeos, slides, áudios, etc., compartilhamento de conteúdo", "A integração entre os colegas de classe", "Aplicar o conhecimento adquirido sobre os assuntos", "Acesso fácil, facilidade, comunicação, debate e rapidez", "A flexibilidade de horários de estudo, a interação com os colegas e as pesquisas realizadas".

Perguntados de qual o seu nível de satisfação em relação a atividade proposta? Responderam: $54,5 \%$ satisfeitos, $40,9 \%$ muito satisfeitos, $4,5 \%$ insatisfeitos. Questionados sobre qual o seu nível de satisfação em relação a forma de se comunicar com os colegas e professor? Responderam: $54,9 \%$ satisfeitos, $34,1 \%$ muito satisfeitos, $11,4 \%$ insatisfeitos. Perguntados qual o seu nível de satisfação em relação ao grupo 
criado? Responderam: 50\% satisfeitos, 45,5\% muito satisfeitos, 4,5\% insatisfeitos. Perguntados qual o seu nível de satisfação em relação a adequação do conteúdo ao tamanho da tela? 59,1\% satisfeitos, $38,6 \%$ muito satisfeitos, $2,3 \%$ insatisfeitos. Questionados sobre qual o seu nível de satisfação em relação a metodologia utilizada na atividade? Responderam: $61,4 \%$ satisfeitos, $31,8 \%$ muito satisfeitos, $6,8 \%$ insatisfeitos. Perguntados ainda qual o seu nível de satisfação em relação ao aplicativo utilizado na atividade? Responderam: $61,4 \%$ satisfeitos, $38,6 \%$ muito satisfeitos, $0 \%$ insatisfeitos.

Podemos citar vários pontos positivos relatados pelos alunos com o WhatsApp: melhorou a relação do professor com os alunos; facilitou os estudos; proporcionou mais tempo para estudar; ajudou a tirar as dúvidas; proporcionou aos alunos ajudar os colegas; facilitou os estudos de temas que não entendiam só com as explicações do professor; ajudou a tirar dúvidas sem ter que esperar até a próxima aula; aumentou a comunicação com o professor; permitiu estudar em qualquer lugar; proporcionou aprendizagem coletiva, colaborativa e trocas de conhecimento; possibilitou adiantar conteúdos; permitiu o uso de vídeos, áudios e imagens para melhor ilustrar o conteúdo; permitiu a criação de grupos para socialização. Permitiu o estreitamento de laços na relação professor e alunos, as aulas passaram a ser "menos chatas" além de sentirem o professor mais presente e atuante dentro e fora da sala de aula.

\section{Considerações finais}

Durante o desenvolvimento da atividade as dificuldades foram esclarecidas pelo professor, consolidando e lapidando os conceitos de forma iterativa fora e dentro da sala de aula. Alguns alunos conseguiram demonstrar aprimoramento na busca por outros conhecimentos. Sentiram à vontade para utilizar o aplicativo com fins pedagógicos mediante a supervisão e orientação planejada do professor. Apreciaram o compartilhamento de materiais, mensagens instantâneas, fazer upload de arquivos, discussões e receber notificações instantâneas. Aprovaram a comunicação e discussão que a ferramenta proporciona entre os alunos e com o professor. Afirmaram que a participação nos grupos do WhatsApp facilitou a promoção do ensino e da aprendizagem dos conhecimentos. Sugere-se, a realização de novos estudos em outra turmas e cursos.

\section{Referências}

Bergmann, J. and Sams, A. (2016). Sala de aula invertida - uma metodologia ativa de aprendizagem. 1. ed. Rio de Janeiro.

Moran, J. M. (2015). Educação híbrida: Um conceito-chave para a educação hoje. In: Bacich, Lilian; Neto, Adolfo Tanzi; Trevisani, Fernando de Mello. Ensino híbrido: personalização e tecnologia na educação. Porto Alegre: Penso.

Saccol, J. B. A.; Schlemmer, E. and Barbosa, J. (2011). M-learning e u-learning: novas perspectivas da aprendizagem móvel e ubíqua. São Paulo: Pearson Prentice Hall.

Souza, C. F. de. (2015). Aprendizagem sem distância: tecnologia digital móvel no ensino de língua inglesa. Revista Texto Livre, v. 8, p. 39-50.

Unesco. (2014). Organização das Nações Unidas para a Educação, a Ciência e a Cultura. Diretrizes de políticas da UNESCO para a aprendizagem móvel. Brasília: UNESCO.

Yin, R. K. (2003). Case Study Research: Design and Methods (3rd Ed.). Thousand Oaks, CA: Sage Publications. 181p. 